\title{
SPATIAL-TEMPORAL CHARACTERISTICS OF THE AEROSOL OPTICAL DEPTH (AOD) DERIVED FROM LONGTERM (1980-2018) MERRA-2 OVER GUANGDONG
}

\author{
Qi Kuang ${ }^{1,2}$, Yunpeng Wang ${ }^{1, *}$ \\ ${ }^{1}$ SKLOG, Guangzhou Institute of Geochemistry, Chinese Academy of Sciences, Guangzhou 510640, P R China - \\ wangyp@gig.ac.cn \\ ${ }^{2}$ University of Chinese Academy of Sciences, Beijing 100082, P R China - kuangqi16@mails.ucas.ac.cn
}

\section{COMMISSION III, WG III/8}

KEY WORDS: AOD, Spatial-temporal Analysis, GDHM, MERRA-2

\begin{abstract}
:
This paper presents and compares the aerosol optical depth (AOD) spatial-temporal characteristics over five subsets in different locations of Guangdong, as well as Hong Kong and Macau (GDHM) since reform and opening-up. By means of GIS analysis tools and subset the onward MERRA-2 monthly mean value aerosol reanalysis dataset to the size of study area, the results reveal that the yearly mean AOD over the whole GDHM ranged from 0.18 to 0.69 during 1980 to 2018. The field average of AOD in five chosen areas approached to 0.40 and appeared linearly increased at 0.0077 per year. All the five selected areas reached their yearly mean AOD peaks at 2007.The field average AOD increased rapidly at 0.028 per year from 1997 till 2007 then appeared decreasing oscillation in a linear slope -0.0109 per year since 2007. But the average AOD of 2010-2018 is higher than the former three decadal averages. Comparing the former and the latter two decades, the high yearly mean AOD value clusters have moved from northern parts of Guangdong to central north Pearl River Delta, where also appeared more apparent AOD yearly change among the other three parts since late 1990s. Only six yearly mean AOD over southern cities of Pearl River estuary were lower than east or west comparing parts in 1980s. Eastern part of Guangdong stayed the lowest yearly mean AOD region in 21 years of the past 39 years. Central, southern and western of GDHM had 36 years while northern and western of GDHM had 37 years their AOD values during February to April were the high values of the year.
\end{abstract}

\section{INTRODUCTION}

The ongoing Modern-Era Retrospective analysis for Research and Applications version 2 (MERRA-2) is a NASA atmospheric reanalysis integrated system for the satellite era using the Goddard Earth Observing System Model, Version 5 (GEOS-5) included the Goddard Chemistry, Aerosol, Radiation, and Transport model (GOCART), and its Atmospheric Data Assimilation System (ADAS), version 5.12.4 project to incorporate aerosol optical depth (AOD) measurements from various NOAA Polar Operational Environmental Satellites (POES), NASA Earth Observing System (EOS) platforms, and NASA ground-based observations that provides global assimilated monthly mean AOD reanalysis gridded data based on their hourly AOD gridded data since January 1980 to present by Goddard Earth Sciences Data and Information Services Center (GES DISC). Bosilovich (2015) and Gelaro (2017) et al have detailed what MERRA-2 system do and the assimilated AOD reanalysis datasets from 1980 to 2015 had been evaluated by study teams of Randles et al $(2016,2017)$. Buchard et al (2017) who had compared and evaluated the MERRA-2 AOD with previous offline long term AOD dataset globally and displayed AOD spatial-temporal average appearances and changes over different population settlements continentally and nationwide.

Inspired by the AOD annual changes study over Yangtze River basin region (He et al., 2018) who also used MERRA-2 monthly AOD, this paper seeks the similarities and differences of the MERRA-2 AOD monthly annual and decadal changes and the AOD distribution pattern over five directional parts of Guangdong province plus Hong Kong and Macau (GDHM) in the past 39 years for further studies.

\section{DATA AND METHOD}

\subsection{Data Description}

The administrative border lines of the study area are shapefiles merged from the data on open GIS source platform, the Google Earth images for extracting the latest coastal line and the National Catalogue Service For Geographic Information (http://www.webmap.cn) for the administrative border names shown in Figure 1 which includes two Special Administrative Region (Hong Kong SAR \& Macau SAR) and Guangdong province which is comprised of twenty-one cities named GDHM. The aerosol optical depth reanalysis dataset is MERRA-2 two dimensional, Monthly mean value, Instantaneous, Single-Level, Assimilation, Aerosol Optical Depth Analysis V5.12.4 (instM_2d_gas_Nx aka M2IMNXGAS 5.12.4) for this long term spatial-temporal study which consists of 468 months NetCDF files from January 1980 to December 2018 which were last downloaded from Goddard Earth Sciences Data and Information Services Center simple subset wizard on May 2019 (GES DISC, 2019). The geographic subset extent for clipping MERRA-2 monthly mean AOD reanalysis dataset is $109.0625^{\circ} \mathrm{W}, 26.2500^{\circ} \mathrm{N}, 117.8125^{\circ} \mathrm{E}$ and $19.7500^{\circ} \mathrm{S}$.

\footnotetext{
* Corresponding author: Y.P. Wang (wangyp@gig.ac.cn)
} 
Each downloaded NetCDF file of study extent has two layers of AOD analysis data, the Aerosol optical depth average value of all the daily values in a month (AODANA) and the increments of the corresponding month (AODINC). This study only uses the AODANA dataset. By the GES DISC provided simple subset wizard, the AOD analysis area is a subset of the global MERRA-2 M2IMNXGAS 5.12.4 .nc file which is a 14 columns by 13 rows grid matrix per month of the total 468 months from January 1980 to December 2018, which cell size is $0.625^{\circ}$ Logintude $0.5^{\circ}$ using GCS_WGS 84 .

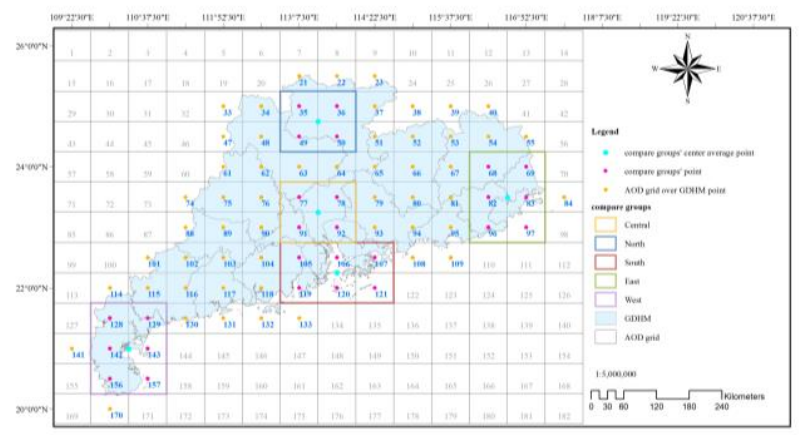

Figure 1. Map showing the 21 Cities of Guangdong province and two Special Administrative Regions Hong Kong and Macau (GDHM), the clipped grids area from MERRA-2

M2IMNXGAS 5.12.4, the groups of grids for comparison, the map is produced by Kuang using ArcMap 10.5.

\subsection{Data Process}

For the purpose to calculate and compare the annual average and annual variation of AOD of the study area, the first step is to number the clipped extent grids of monthly mean AOD. This study derives the MERRA-2 AOD monthly mean value from each geographical central point of the grid cell into a point matrix table per month, which has identical sequence (named pointid) started from 1 to 182 from the top left to the bottom right. The pointid numbers that just cover the study area are appeared in Figure 1. The 468-monthly mean AOD value tables were appended into AOD time series table of totally 85176 rows of point data. As the extent of clipped 14 columns time 13 rows grid of monthly mean AOD is larger than the real extent of GDHM, use two ways to show the annual mean AOD variation of the GDHM. Both two ways are based on Geographic information overlay and identify tools for vector type data by ArcMap and its attribute table selection and linkage. Figure 1 also shows the selected out 79 number identified points of monthly AOD grid cell center that cover GDHM. The first way is based on this point Identity Number (pointid) series to pick up 4-6 AOD grid cells to form a rectangle as a study region group, chose five regions of GDHM, the central, the north, the south, the east and west to compare the AOD monthly and yearly average appearance and changes and find differences of these areas. The average of the group member points' monthly AOD values forms AOD monthly time series of the group area. The yearly time series are based on the calculation of the group areas' monthly AOD time series. And the inter-annual average AOD of the group areas are based on their yearly AOD results. The division of the five groups is listed in Figure 1 and Table1.

The other way uses the map of GDHM to identified extract the 14 columns time 13 rows monthly AOD grid into the shape of 21 cities in Guangdong province plus Hong Kong and Macau into 39 years AOD annual mean spatial distribution that remain original AOD grid cell borderline to see the yearly AOD spatial pattern variation range. These annual results are shown in Figure 4.

\begin{tabular}{|c|c|c|}
\hline Group & $\begin{array}{l}\text { Grid cell central } \\
\text { point ID }\end{array}$ & Major Covered cities \\
\hline Central & $77,78,91$ and 92 & $\begin{array}{l}\text { Guangzhou, Foshan and } \\
\text { Dongguan }\end{array}$ \\
\hline North & $35,36,49$ and 50 & $\begin{array}{l}\text { Shaoguan, } \\
\text { northeast }\end{array}$ \\
\hline South & $\begin{array}{l}105, \quad 106, \quad 107, \\
119,120 \text { and } 121\end{array}$ & $\begin{array}{l}\text { Macau, Zhuhai, Zhongshan, } \\
\text { Jiangmen Shenzhen and Hong } \\
\text { Kong }\end{array}$ \\
\hline West & $\begin{array}{l}128, \quad 129, \quad 142, \\
143,156 \text { and } 157\end{array}$ & Zhanjiang \\
\hline East & $\begin{array}{l}68,69,82,83,96 \\
\text { and } 97 .\end{array}$ & $\begin{array}{l}\text { Shantou, Chaozhou and } \\
\text { Jieyang, Meizhou southeast }\end{array}$ \\
\hline
\end{tabular}

Table1. Compare groups of AOD cell central points

\section{RESULT AND DISCUSSION}

\subsection{AOD Monthly Mean Trends}

The AOD monthly mean trends of the five group areas are shown in Figure 2. All the five trends during the 468 months of the years between 1980 and 2018 have monthly peaks and valleys of AOD in the same period while the value of peaks and values of valleys of each group are different. There were 217 months that the monthly mean AODs over the central area of GDHM are higher than the monthly AODs over the other four groups of areas; 168 months that the monthly mean AODs over the north area of GDHM are higher than the monthly AODs over the other four groups of areas; 27 months that the monthly mean AODs over the south area of GDHM are higher than the monthly AODs over the other four groups of areas; 10 months that the monthly mean AODs over the east area of GDHM are higher than the monthly AODs over the other four groups of areas; 46 months that the monthly mean AODs over the west area of GDHM are higher than the monthly AODs over the other four groups of areas. The highest AOD monthly mean among the values of these five groups was the average value of central group grids of GDHM, March 2010, 1.33 (round to two decimals).

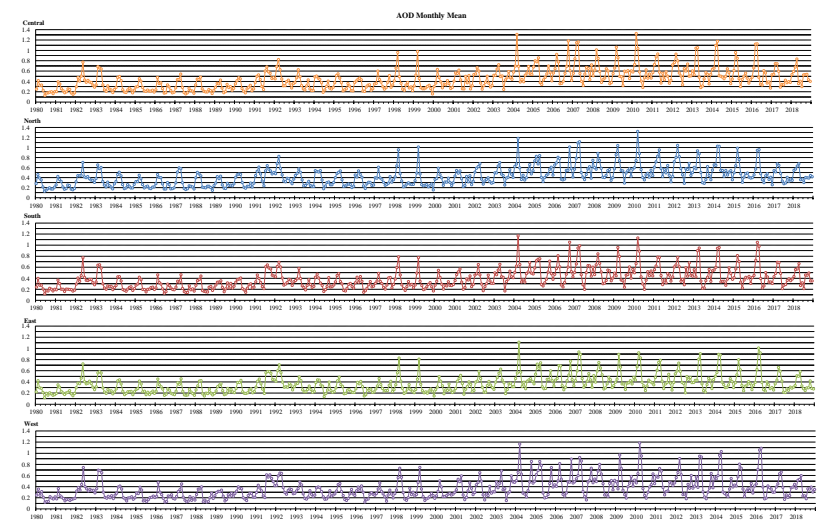

Figure 2. Monthly AOD trend after calculating the average of the AOD grids that form the comparing group, from top to bottom are the monthly AOD trend of Central, North, South, East and West of GDHM areas. 
Since SURFRAD Aerosol Optical Depth states that AOD value of 0.4 would correspond to a very hazy condition (https://www.esrl.noaa.gov/gmd/grad/surfrad/aod/), the count months of the AOD monthly average value of the five groups of areas that is over 0.4 by the time period division 1980-2018, 1980-1989, 1990-1999, 2000-2009 and 2010-2018 are shown in Table 2 .

The result in Table 2 reflects that central and north of GDHM areas more than half of the months during 1980 to 2018 had aerosol optical depth over 0.4 hazy air conditions. South of GDHM areas had near $40 \%$ of 468 months were hazy. East and west coastal areas of GDHM had more than $31 \%$ of these months were in hazy air conditions. 2000-2009 is the most period of the months AOD over 0.4 for all the five compared groups of areas. The spread of the AOD over 0.4 months count between 1990-1999 and 2000-2009 from large areas to small areas follows as west, south, east, central and north. The spread of the AOD over 0.4 months count between 2000-2009 and 2010-2018 from large areas to small areas follows as west, east, and south, central and north. The north group areas are the only one area that its AOD over 0.4 months number increased in all the four time periods.

\begin{tabular}{lcrrrr}
\hline groups & $1980-$ & $1980-$ & $1990-$ & $2000-$ & $2010-$ \\
& 2018 & 1989, & 1999 & 2009 & 2018 \\
\hline Central & 239 & 23 & 44 & 87 & 85 \\
North & 237 & 27 & 45 & 82 & 83 \\
South & 180 & 13 & 30 & 72 & 65 \\
East & 148 & 15 & 27 & 58 & 48 \\
West & 147 & 9 & 22 & 65 & 51 \\
\hline
\end{tabular}

Table 2. Count months of the AOD monthly average value over 0.4

\subsection{AOD Yearly Mean Trends}

The AOD yearly mean of the five groups, the AOD yearly mean of the average of the five groups, the average AOD of the thirty nine years (1980-2018) of each group and of the group average are shown in Figure 3 with three time groups, 19801997, 1997-2007 and 2007-2018 to compare AOD yearly average variation gradient over each group of GDHM and the average of the five groups using linear regression.

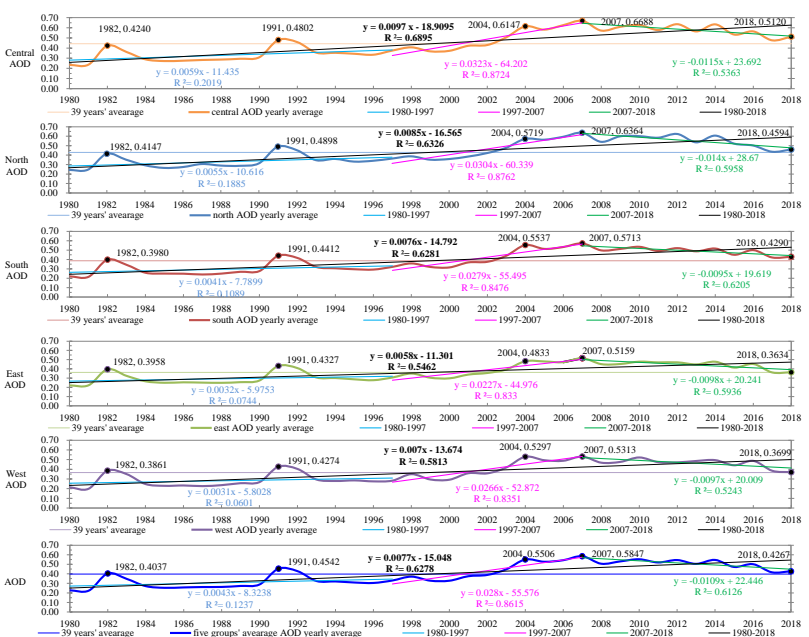

Figure 3. From top to bottom are the AOD yearly average trends of central, north, south, east and west of GDHM areas and the average AOD trend of the five groups' yearly average AODs during 1980-2018.
Figure 3 shows the calculated MERRA-2 AOD yearly trends over all the five group of grids area appear similar at the point of year 1982, 1991, 2004, 2007 and 2018. AOD yearly average values of all the five groups in 1982, 1991, 2004 and 2007 were the peaks among values of their former one year and their latter one year. Seeing the linear regression line (the cyan straight line 1980-2007) of yearly AOD from 1980 to 1997, the yearly AOD of central, north, south, east and west, these five group of grids all appear merely slow increase, with two interval maximum values in 1980s and in 1990s as MERRA-2 assimilated model runs the global effect of volcano aerosol by the two famous volcano eruptions in 1982 and 1991, the MERRA-2 aerosol optical depth data assimilation team has specified the volcano eruption and satellite observation instruments effect for aerosol assimilation results of both stratosphere and troposphere (Randles et al, 2016). In 1980-1997, prior to Earth Observation System (EOS) era, the MERRA-2 AOD yearly variation linear regression slope of the five compared groups of AOD monthly grids ranks from high to low as central, north, south, east and west. The $\mathrm{R}^{2}$ of linear regression of all the five areas in 19801997 are so small that one linear regression is not fit to explain the variation of each group during this period. The AOD yearly average increased apparently from 1997 to 2007, AOD yearly average of central group linear regression line increased slope is higher than the value of the north group but the $\mathrm{R}^{2}$ of central group trend is lower than the $\mathrm{R}^{2}$ of the north group in this period. The south group AOD yearly average linear increase slope from 1997 to 2007 is the median among the five groups. West group AOD yearly average increased more apparently than the East group in this period especially during the years between 2002 and 2004. 2007 is the assimilated AOD yearly average peak year during the thirty-nine years period for all the five groups of areas of Guangdong, Hong Kong and Macau of China. The AOD of 2007 over these five areas ranks from high to low is central, north, south, west and east. Since 2007 till 2018the yearly AOD over the five areas all have turned slowly decreasing as linear regression lines shown in Figure 3 which the absolute values of the descending line slopes are all smaller than the slope value of the ascending period of 1997 to 2007 . AOD yearly average in the period of 2007 to 2018 over South area of GDHM decreased least apparent annually but the $\mathrm{R}^{2}$ of the linear regression line is the highest among the five areas while AOD yearly average over north area of GDHM descending slope value is the biggest among the five. Central AOD yearly average declining slope in 2007-2018 is the second largest. The difference of AOD yearly average descending slopes between the two low AOD yearly average areas, the East group and the West group is 0.0001 . The linear regression of the thirty-nine years AOD yearly average lines of the five groups of areas and the five areas' average shown in Figure 3 indicate that AOD yearly average over central of GDHM increased linearly the fastest among the five areas, north, south, west and east ranks the second to the fifth place each other. The yearly AOD of the five areas' average appearance in the bottom chart of Figure 3 shows its annual linear increased rate in the period of 1997 to 2007 and annual linear decreased rate in the period of 2007 to 2018 are the values bigger than the value of south, east and west meanwhile smaller than the value of north and central.

The five AOD yearly average variation lines all appeared oscillation in the period 2007 to 2018 in Figure 3. Each group average AOD of 2018 is larger than its thirty-nine years' average AOD and its average AOD of 2017. Only the east group and the west group 2017 average AOD are smaller than 
their own thirty-nine years' average values. The difference values between the 2018 average AOD and the thirty-nine years' average AOD are 0.0693 of central, 0.0306 of north, 0.0424 of south, 0.0013 of east, 0.0035 of west and 0.0294 of the five groups' average.

Figure 4 presents the spatial distribution variation of annual average of AOD over the whole area of Guangdong, Hong Kong and Macau of China from 1980 to 2018 which remain the grid resolution of MERRA-2 monthly AOD datasets where the yearly AOD grid covered place minimum value was more than 0.18 in 1981 and the maximum value was less than 0.69 in 2007. In the period of 1980 to 2018 , relative high to maximums of every year AOD annual average regions cover the cities such as Guangzhou, Foshan, Dongguan and Shaoguan, particularly the areas represented by the AOD grid central point identity numbers (pointid) that followed as $36,49,50,63,77,91$. Point identity numbers 69, 83, 96, 97, 156 and 157 representing regions where AOD annual averages are relative low to the minimums of every year. These 39 years patterns of AOD yearly average spatial distribution cluster out the AOD total high area, the central and northwest part of the Guangdong province and the AOD total low area, the east coastal part and southwest coastal part of Guangdong province. The south part of GDHM, the cities parts along the estuary of Pearl River appears median level of yearly average of AOD range every year.
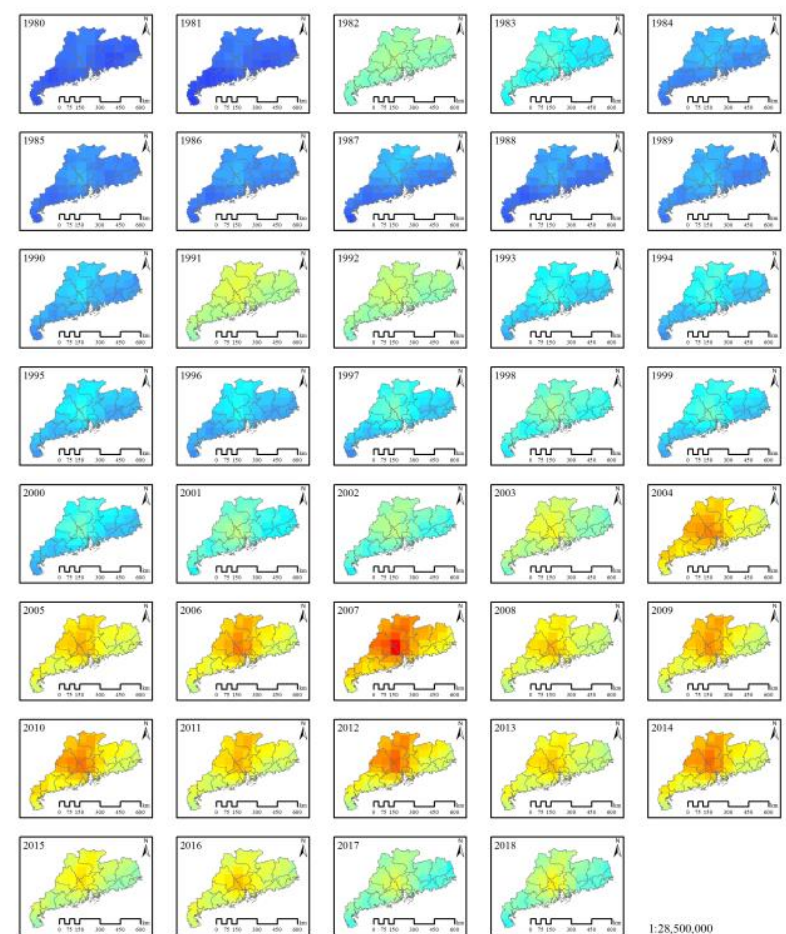

1980-2018 annual average of AOD over Guangdong, Hong Kong, Macau of China

annual average of $A O D$ range

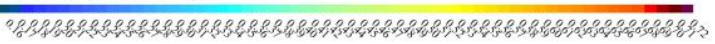

Figure 4. Spatial distribution patterns of yearly average AODs from 1980 to 2018. The map is produced by Kuang using ArcMap 10.5.

\subsection{AOD Inter-annual Average Comparison}

The AOD average of the past thirty-nine years spatial distribution of the Guangdong plus Hong Kong and Macau is presented in Figure 5. The map shows the Central group grids cover areas average AOD is over 0.44 , the North group grids cover areas average AOD is near 0.43 , the South group grids cover areas average AOD is near 0.39, the West group grids cover areas average AOD is near 0.37 and the East group grids cover areas average AOD is over 0.36. The AOD total average of the five groups in thirty-nine years is about 0.40 .

Figure 6 provides the distribution of average AOD of each decade over GDHM in the thirty-nine years. Figure 7 and Figure 8 shows the MERRA-2 AOD decadal averages comparison among the five groups of areas. Figure 6 presents the AOD average of 1980s distribute values over the whole area of GDHM range over 0.18 to around 0.3. In the 1990s AOD average range went up to between 0.3 and 0.4 . In the 2000 s AOD average range is around 0.4 to around 0.55 . AOD average in the most recent nine years range went up to around 0.45 to near 0.6 although the AOD yearly average appeared mildly shake down every year since 2007.

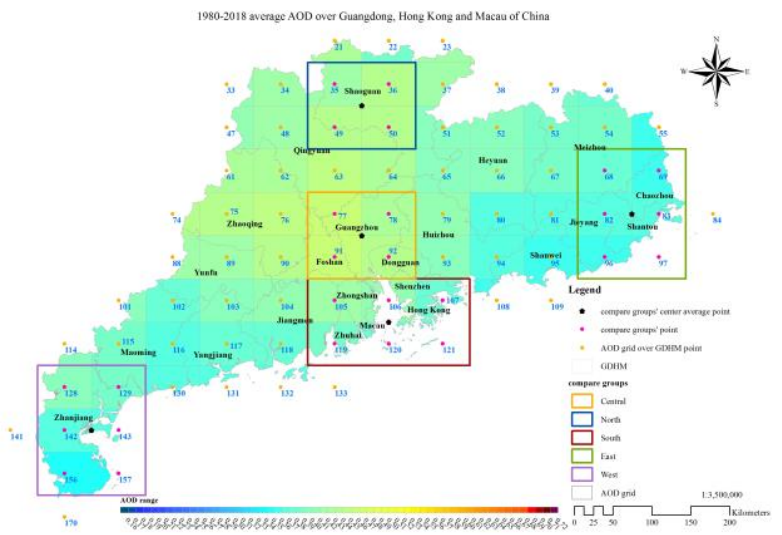

Figure 5. $1980-2018$ average AOD spatial distribution. The map is produced by Kuang using ArcMap 10.5.

Considering the grid resolution cell border line and the city border line, the maps in Figure 6 also present that west part of Guangzhou, most part of Foshan, central south of Shaoguan and central south of Qingyuan are always the areas with the higher AOD yearly average than the in these four time groups. AOD averages of the west side of Guangzhou divided by the grid line are always higher than the values of the east side of Guangzhou in each decadal period.

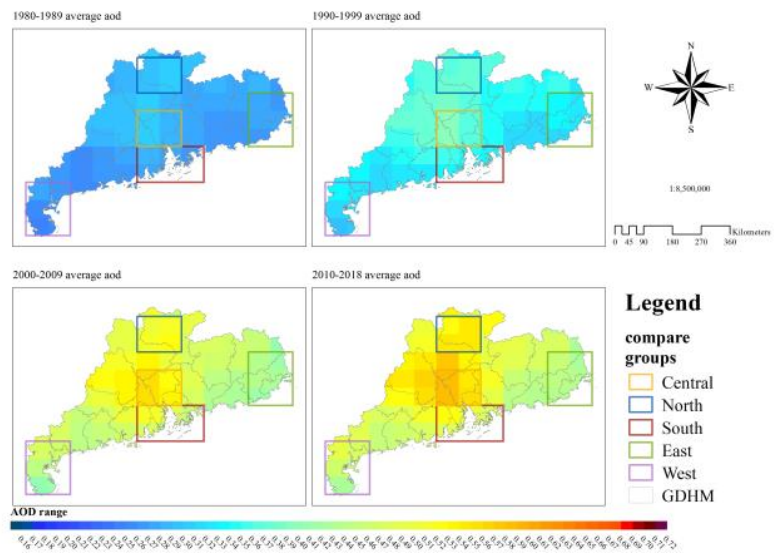


Figure 6. Map of the spatial distribution of AOD decadal average over GDHM in 1980s, 1990s, 2000s and 2010s. The Map is produced by Kuang using ArcMap 10.5.

The AOD decadal average variations of the five groups are different to each other among the thirty-nine years shown in Figure 7. In 1980-1989 the value of north group was the largest among the other four groups. In the latter three decades the decadal average values of the central group areas were the top of the values of the other four groups and the north groups ranked the second place. AOD decadal average of the south group area of GDHM ranked the fourth place after the east group area of GDHM in 1980-1989 then it ranked the third place from 1990 to 2018. AOD decadal average of west group area of GDHM, ranked the lowest place in the first twenty years, then it ranked the fourth place in the latter twenty years.

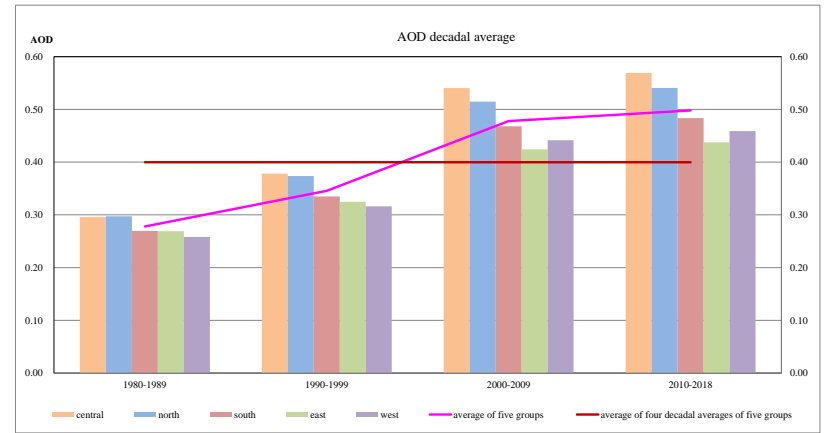

Figure 7. The comparison among AOD decadal average of the five groups

The ranks of the AOD decadal average values of the east group area of GDHM went down from the third place to the bottom place through the thirty-nine years. The AOD average of the five groups of areas in 1980-1989 was less than 0.3, and then the value went to near 0.35 in 1990-1999 and then the value went up greatly to near 0.48 in 2000-2009 and then went up a little to near 0.5 in 2010-2018.The difference between the AOD average of the former twenty years and the AOD average of the latter nineteen years is shown in Figure 8. The difference ranks from high to low as central, north, south, west and east. The difference between the two straight lines which represent the five groups' average AOD in 1980-1999 and 2000-2018 is about 0.18 .

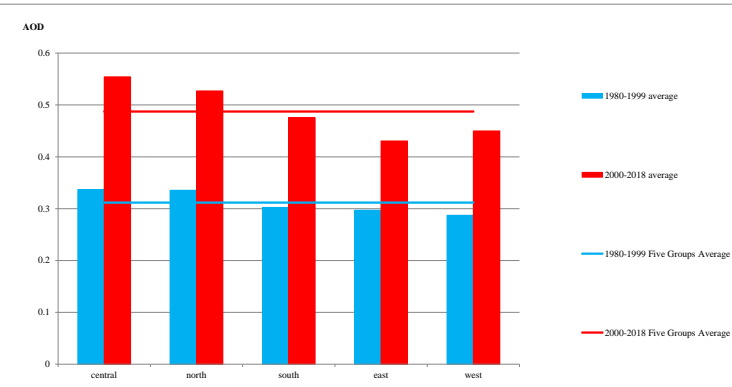

Figure 8. The comparison among the five groups of GDHM between the average AOD in 1980-1999 and the average AOD in $2000-2018$

\section{CONLUSION}

Considering that the grid resolution of MERRA-2 aerosol optical depth reanalysis dataset it only can present total average level of AOD over grand city area. The data present above show that monthly average AOD in the five compared groups all had high values between February and April. The spatial distribution of the yearly average of AOD and the decadal average of AOD both show the high AOD place in the whole GDHM moved from northern GDHM in 1980s and first half of 1990s to central north of Pearl River Delta cities areas with highly developed industrial economy, high population density and busy traffic since late 1990 s till present. Considering the AOD over 0.4 months count variation among the time periods of 1990-1999, 2000-2009 and 2010-2018, the north selected areas is the least variation place while the west selected areas is the most variation place. All the five chose areas for comparison had peak yearly average AOD in 2007, since then the yearly average of AOD over these five places appeared a decreasing tendency which reflects some achievement of those air pollution control measures from 2007 to present. The MERRA-2 AOD reanalysis data discussed in this paper is total average of the satellite and ground based observation assimilated data which neither distinguish aerosol sources nor consider the optical depth of different aerosol chemical types but provides spatio-temporal variation patterns of AOD in grand city level. Further study will use the aerosol diagnostic and its extended version of MERRA-2 aerosol reanalysis dataset to discuss the optical depth spatio-temporal distribution of sulphate, black carbon, organic carbon, dust and sea salt over Guangdong, Hong Kong and Macau of China.

\section{ACKNOWLEDGEMENTS}

Guangdong NSF (2017A030310D05) and State Key Laboratory of Organic Geochemistry Program (SKLOGA201603A) are acknowledged for financial supports. This paper is particularly grateful to the NASA Global Modeling and Assimilation Office for providing the MERRA-2 aerosol reanalysis data. And much appreciated to other GIS open data providers for administrative map.

\section{REFERENCES}

Bosilovich, M. G., Akella, S., Coy, L., Cullather, R., Draper, C., Gelaro, R., Kovach, R., Liu, Q., Molod, A., Norris, P., Wargan, K., Chao, W., Reichle, R., Takacs, L., Vikhliaev, Y., Bloom, S., Collow, A., Firth, S., Labow, G., Partyka, G., Pawson, S., Reale, O., Schubert, S. D., and Suarez, M., 2015. MERRA-2: Initial Evaluation of the Climate, Technical Report Series on Global Modeling and Data Assimilation, 43, doi.org/ NASA/TM-2015104606/VOL.43, GSFC-E-DAA-TN29739

Buchard, V., Randles C.A., da Silva, A.M., Darmenov, A., Colarco, P. R., Govindaraju, R., Ferrare, R., Hair, J., Beyersdorf, A. J., Ziemba, L. D., and Yu, H., 2017. The MERRA-2 Aerosol Reanalysis, 1980 - Onward, Part II: Evaluation and Case Studies. J. Climate, 30, 6851-6872, doi.org/10.1175/JCLI-D16-0613.1

Gelaro, R., McCarty W., Suárez M. J., Todling R., Molod A., Takacs L., Randles, C. A., Darmenov, A., Bosilovich, M. G., Reichle, R., Wargan, K., Coy, L., Cullather, R., Draper, C., Akella, S., Buchard, V., Conaty, A., da Silva, A. M., Gu, W., Kim, G., Koster, R., Lucchesi, R., Merkova, D., Nielsen, J. E., Partyka, G., Pawson, S., Putman, W., Rienecker M., Schubert S.D., Sienkiewicz M., and Zhao B., 2017.The Modern-Era Retrospective Analysis for Research and Applications, Version 2 (MERRA-2). J. Climate, 30, 5419-5454, doi.org/10.1175/JCLI-D-16-0758.1 
Global Modeling and Assimilation Office (GMAO) (2015), MERRA-2 instM_2d_gas_Nx: 2d, Monthly mean, Instantaneous, Single-Level, Assimilation, Aerosol Optical Depth Analysis V5.12.4, Greenbelt, MD, USA, Goddard Earth Sciences Data and Information Services Center (GES DISC), doi.org/10.5067/XOGNBQEPLUC5

He, L. J., Wang, L. C., Lin, A. W., Zhang, M., Xia, X. G., Tao, M. H., Zhou, H., 2018. What drives changes in aerosol properties over the Yangtze River Basin in past four decades? Atmospheric Environment, 190, 269-283. doi.org/10.1016/j.atmosenv.2018.07.034.

Randles, C. A., da Silva, A. M., Buchard, V., Darmenov, A., Colarco, P. R., Aquila, V., Bian, H., Nowottnick, E. P., Pan, X., Smirnov, A., Yu, H., and Govindaraju, R., 2016. The MERRA2 Aerosol Assimilation, NASA Technical Report Series on Global Modeling and Data Assimilation, 45, doi.org/NASA/TM -2016-104606, Vol. 45, pp. 1-153, 2016.

Randles, C. A., da Silva, A. M., Buchard, V., Colarco, P. R., Darmenov, A., Govindaraju, R., Smirnov, A., Holben, B., Ferrare, R., Hair, J., Shinozuka, Y., and Flynn, C. J., 2017. The MERRA-2 Aerosol Reanalysis, 1980 - Onward, Part I: System Description and Data Assimilation Evaluation. J. Climate, 30, 6823-6850, doi.org/10.1175/JCLI-D-16-0609.1 